\title{
A ESCOLA ENTRE OS EMBATES NA PANDEMIA
}

\author{
Raquel Goulart Barreto ${ }^{1}$
}

RESUMO: Com base na análise crítica do discurso, este artigo objetiva trazer referências à escola em meio à pandemia, em seus aspectos semânticos, sintáticos e pragmáticos. Para seu dimensionamento, explicita as atuais condições de possibilidade de formulações em disputa por hegemonia, focando na incorporação educacional das Tecnologias de Informação e Comunicação como substituição do trabalho docente. No que diz respeito às perspectivas pós-pandemia, analisa os sentidos das propostas de ensino híbrido, nas suas relações com o uso intensivo das plataformas privadas na escola pública.

Palavras-chave: Políticas educacionais. Discursos. Escolas, Trabalho docente.

\section{THE SCHOOL AMONG THE CLASHES IN THE PANDEMIC}

\begin{abstract}
Based on a critical discourse analysis, this article aims at bringing references to the school during the pandemic, in its semantic, syntactic, and pragmatic aspects. In approaching them, it elicits the current possibility conditions of formulations struggling for hegemony, focusing on the educational incorporation of Information and Communication Technologies as a replacement of teaching work. Regarding the post-pandemic perspectives, it analyzes the meanings of hybrid teaching ('blended learning') proposals, in their relations with the intensive use of private platforms in public schools.
\end{abstract}

Keywords: Educational policies. Discourses. Schools. Teaching work.

\section{LA ESCUELA ENTRE LOS ENFRENTAMIENTOS EN LA PANDEMIA}

RESUMEN: A partir del análisis crítico del discurso, este artículo tiene como objetivo traer referencias a la escuela en medio de la pandemia, en sus aspectos semánticos, sintácticos y pragmáticos. Para su dimensionamiento, explica las condiciones actuales de posibilidad de formulaciones en disputa por la hegemonía, centrándose en la incorporación educativa de las Tecnologías de Información y Comunicación como sustituto del trabajo docente. Con respecto a las perspectivas futuras, analiza los significados de las propuestas de enseñanza híbrida, en sus relaciones con el uso intensivo de plataformas privadas en las escuelas públicas.

Palabras-clave: Políticas educativas. Discursos. Escuelas. Trabajo docente.

Baseado na pesquisa "Dimensões da Substituição Tecnológica nas Políticas Educacionais: O Caso da Secretaria Municipal do Rio de Janeiro”, financiada pelo CNPq com Bolsa de Produtividade em Pesquisa (Processo: 311188/2015-0).

1.Faculdade de Educação - Programa de Pós-graduação em Educação - Universidade do Estado do Rio de Janeiro - Rio de Janeiro (RJ), Brasil.E-mail: raquel@uol.com.br

Editor de Seção: Antonio Alvaro Soares Zuin 


\section{A Via do Discurso}

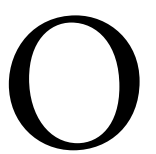

presente artigo visa analisar criticamente os discursos sobre a escola no contexto da pandemia do novo coronavírus (Sars-CoV-2), mais conhecida como pandemia da Covid-19. Sobre diferentes dimensões desse contexto têm sido publicados artigos importantes, como os de Oliveira e Pereira (2020), abordando a questão da desigualdade educacional brasileira; Gusso et al., (2020), estabelecendo diretrizes à gestão universitária; e Adrião e Domiciano (2020), focando nas corporações e no uso das plataformas digitais. Também cabe destacar lives realizadas ao longo de 2020, com as participações de Leher e Pretto. A pretensão é contribuir para uma perspectiva que favoreça a abordagem de relações entre esses trabalhos, tendo em vista o modo de objetivação do discurso assumido.

$\mathrm{Na}$ formulação da análise crítica de discurso (ACD) (FAIRCLOUGH, 2001, 2006), o adjetivo pretende marcar a diferença em relação ao movimento, cada vez mais comum, de pensar a linguagem desprovida de exterior. Para dimensionar o discurso em relação ao que não o é, o autor propõe uma abordagem tridimensional, tomando-o como texto, na sua materialidade; como prática discursiva, compreendendo produção, distribuição e consumo; e como prática social, "firmemente enraizada em estruturas sociais materiais, concretas, orientando-se para elas" (FAIRCLOUGH, 2001, p. 93). Assim, a abordagem sustentada pela ACD não exclui as questões que adquirem materialidade mais espessa do que a da linguagem.

Em outras palavras, o discurso constitui matéria a ser investigada no conjunto das suas condições de possibilidade. O que faz com que as ideias adquiram "performatividade" é a sua congruência com o que não é discurso; ou seja, com a base da vida material. Logo, como modo de ação marcado pela relação dialética com a estrutura social, a ACD permite "investigar as práticas discursivas como formas materiais de ideologia" (FAIRCLOUGH, 2001, p. 116). No que diz respeito a essa última, a formulação retoma o conceito gramsciano de hegemonia para analisar os movimentos de entrega e resistência dos sujeitos aos sentidos sedimentados e aos deslocamentos possíveis. O que se busca é a compreensão dos mecanismos constitutivos da luta pela legitimidade dos diferentes sentidos, já que, em meio aos sentidos historicamente possíveis, um tende a ser mais "lido" que os outros: é formalizado e legitimado, enquanto os demais podem nem sequer cogitados. Em outras palavras, em perspectiva histórica discursiva, a ideologia corresponde à hegemonia do sentido.

Se a constituição do corpus é nuclear nas diferentes trajetórias analíticas, em se tratando de uma abordagem nitidamente processual - isto é, sem poder contar com desfechos, ainda que provisórios -, a tarefa exige exame mais acurado das possibilidades e limites implicados. No caso, o recurso sistemático a reportagens foi uma alternativa para captar as vozes dos diferentes sujeitos. Por outro lado, algumas limitações não podem ser minimizadas, como a velocidade com que as reportagens devem ser registradas. Outra limitação é sua própria configuração textual, que, em função da brevidade desejável, tende a não contemplar relações e argumentos. Outra, ainda, mais fundamental, diz respeito à presença sistemática de uma forma de discurso indireto, em que os espaços abertos às falas dos sujeitos são administrados por aqueles a quem cabe veicular essas mesmas falas. É o que ocorre, por exemplo, em transcrições de entrevistas, individuais ou coletivas, de autoridades constituídas.

A menção a autoridades constituídas torna oportunas outras considerações acerca do corpus deste estudo. Uma delas é a ausência da pretensão de dar conta de todo o Brasil. Outra, não menos importante, é o fato de que o Governo Federal assumiu postura negacionista, de modo que estados e municípios foram tomando decisões acerca dos procedimentos a serem adotados no enfrentamento à pandemia, tendo sido a crise política materializada como embate entre discursos diversos, muitas vezes intermediados juridicamente. Em nível nacional, o negacionismo remeteu a falas desconectadas dos desafios a serem enfrentados, em deslocamentos que têm favorecido mais a produção de memes, muitas vezes como folclorização de aberrações sucessivas. Por essa razão, o discurso da presidência não é objeto de análise neste trabalho. ${ }^{1}$ 
No contexto da pandemia, o embate central continua sendo a reabertura das escolas para as aulas presenciais. Em outras palavras, as escolas estão postas na confluência de pelo menos três pares de opostos nos discursos: 1) econômico vs. científico; 2) público vs. privado; e 3) técnico vs. político. É possível haver contestação a esses pares, especialmente ao último, uma vez ultrapassados os limites da lógica formal, mas eles permitem organizar o modo de aproximação da realidade representada/referida nos textos circulantes.

No que tange à empreitada analítica, é preciso reconhecer que os objetos empíricos dos quais se parte em busca do discurso não são transparentes. Não há como simplesmente atravessar os textos. O trabalho com eles requer decisões acerca dos pontos de entrada a serem estabelecidos. Nessa definição, é importante focar em três aspectos: o semântico, o sintático e o pragmático.

\section{Pontos de Entrada nas Práticas Discursivas}

O aspecto semântico, por compreender significados e sentidos, tende a ser o mais comum nas análises. Entretanto, as questões discursivas não se esgotam no nível das palavras e expressões. Tendo em vista que significados e sentidos são históricos, é preciso ultrapassar a discussão das escolhas lexicais para compreender os processos que as sustentam.

Cabe considerar, por exemplo, as metáforas escolhidas para "descrever" a realidade. Como a "roletarussa da abertura das escolas", no título de artigo que discute o tema (CÁSSIO; CORTI, 2020). Igualmente, vale a citação do suposto "mesmo barco", feita pela presidente da Fundação Oswaldo Cruz (Fiocruz), Nísia Trindade Lima (RIBEIRO, 2020). Contrariando a expectativa de um discurso estritamente médico-sanitário, Nísia afirma:

A pandemia não é a mesma para todos os países, nem a mesma para todos dentro de um mesmo país ou da mesma cidade. Muitos dizem que estamos todos no mesmo barco, mas não é bem assim. Estamos todos passando pela mesma tempestade no mesmo mar. Mas é como se alguns estivessem em transatlânticos, outros em iates, outros em barcos a vela ou mesmo canoas [...] o alastramento da Covid-19 é uma emergência sanitária e humanitária multidimensional. Enfrentá-la de modo efetivo só é possível com a reafirmação da importância científica e o alinhamento dos conhecimentos vindos de todas as áreas da ciência.

Num país com muitas desigualdades, o vírus pode evidentemente atingir a qualquer um, mas uns podem se resguardar melhor do que outros, visto que milhões de brasileiros sequer têm acesso a água limpa e encanada e que, para muitos, evitar aglomerações soa como uma utopia (RIBEIRO, 2020). ${ }^{2}$

Ainda do ponto de vista semântico, cabe sublinhar os processos de ressignificação e relexicalização. Os primeiros compreendem a atribuição de sentidos novos a palavras dicionarizadas, em deslocamentos que tendem a marcar sua inscrição em matrizes outras. É o que se pode observar, por exemplo, em relação à "aprendizagem". A palavra é mantida, mas pode designar simplesmente "acesso" ao conhecimento produzido. Quanto aos últimos, dizem respeito à utilização de neologismos ou de termos já cunhados em outras áreas e para outros fins, com o objetivo de dar conta de sentidos que as palavras existentes parecem não expressar. É o caso de "objetos de aprendizagem" em substituição a "materiais de ensino".

No contexto da pandemia, algumas expressões são dignas de nota. É o que ocorre em "ensino remoto emergencial”, em que a adjetivação sucessiva remete a possibilidades até então não pensadas. Embora seja possível fazer uma abordagem técnica centrada nas suas aproximações e nos seus distanciamentos em 
relação ao ensino ou à aprendizagem a distância (HODGES et al, 2020), é preciso destacar a flexibilização e a justificativa embutidas na expressão: o que for exequível, enquanto durarem as condições excepcionais.

Em síntese, a análise dos processos de significação sustenta a caracterização dos movimentos de abandono, deslocamento e/ou apropriação de palavras e expressões em diferentes contextos e matrizes conceituais, assim como de cunhagem de outras palavras e expressões para dar conta de novos aspectos da "realidade". Entretanto, os aspectos semânticos, por si, não dão conta das múltiplas questões que constituem as práticas discursivas, questões essas que não envolvem apenas escolhas lexicais, mas as relações estabelecidas entre as tais escolhas e os modos pelos quais os sujeitos se relacionam com o que dizem. Daí a importância dos aspectos sintáticos e pragmáticos.

Os aspectos sintáticos, compreendidos como as relações entre as escolhas feitas, remetem à análise de diferentes ordenamentos na produção dos discursos. O mais evidente deles é a constituição dos sujeitos, na qual deslocamentos sucessivos podem atingir mudanças radicais, como o movimento de atribuir a objetos ações que só poderiam ser desenvolvidas por sujeitos. É o caso do posicionamento de objetos como sujeitos (BARRETO, 2017) - com todas as suas consequências - recorrente nas formulações acerca das "soluções" que as Tecnologias da Informação e da Comunicação (TIC) "trazem” para a educação.

A constituição dos sujeitos é, portanto, central na análise dos discursos em circulação. Considere-se, por exemplo, dois excertos de entrevistas concedidas por Marcelo Crivella, então Prefeito do Rio de Janeiro. O primeiro evidencia uma forma peculiar de apropriação do cientista:

- Todos sabem que as crianças do mundo inteiro são imunes. Se voe [sic] olhar por exemplo, os casos de coronavírus na cidade do Rio de Janeiro. Das milhares de pessoas que faleceram, $80 \%$ são pessoas acima de 60 anos. Os outros $20 \%$ de 40 a 60 anos. É difícil um caso de criança que faleceu... Então, graças a Deus, no mundo inteiro, as crianças estão imunes ao coronavírus. O problema é serem portadoras e passarem para o vovô e a vovó. O protocolo vai nesse caminho - disse Crivella ao responder uma pergunta se a prefeitura já tinha estabelecido um protocolo de medidas sanitárias para a volta às aulas (CRIVELLA..., 2020).

O sujeito que sugere a inclusão ("todos") é acompanhado por "sabem”, compondo uma formulação que permite a desqualificação dos que não sabem ou discordam. A postura autoritária se articula à remissão ao discurso religioso ("graças a Deus") e, ainda, ao tom popular adotado ("o vovô e a vovó"). A afirmação é feita de modo categórico, afastando questionamentos, embora dados do Painel Rio Covid-19, da própria Prefeitura, informem que a cidade registrou quinze mortes pela doença na faixa etária de 0 a 9 anos de idade, e outras dez na faixa entre 10 e 19 anos.

O segundo excerto implica uma forma de transferência de responsabilidade, uma vez posta a relação estreita com o econômico, já que o fechamento das escolas não pode ser separado do fornecimento de merenda escolar. Mais tarde, na mesma data, o formulador afirma que essa ausência seria uma punição para o desvio ("teve muita gente usando o cartão para comprar cachaça e cigarro"), aplicada por outrem ("o Ministério Público proibiu o cartão”):

Mães de alunos da rede municipal de ensino do Rio afirmam que estão sem condições de alimentar os filhos durante a pandemia da Covid-19. Elas reclamam que a Prefeitura não está fornecendo cestas básicas ou recarregando o cartão do auxílio-merenda, que dá direito a $\mathrm{R} \$$ 100 durante pandemia. [...] 
Na última semana, uma mãe questionou o prefeito Marcelo Crivella sobre a recarga do cartão. “Teve muita gente usando o cartão para comprar cachaça e cigarro. [...] O que aconteceu foi o seguinte: é que o Ministério Público proibiu o cartão", respondeu o prefeito.

O Ministério Público desmentiu o prefeito e esclareceu não ter conhecimento sobre a expedição de recomendação ou de ações na justiça pedindo a proibição da distribuição ou recarga de cartões alimentação.

No mesmo dia, o prefeito Marcelo Crivella prometeu a entrega de uma cesta básica para cada aluno da rede pública de ensino. Apesar disso, algumas mães não conseguiram adquirir o benefício (LUCHESE, 2020).

A reabertura das escolas permanece como embate central, bem como a explicitação dos sujeitos responsáveis pelas suas consequências. Entre as supostas "soluções", é possível verificar tentativas de "desresponsabilização" pelas autoridades, ajudando a prevenir eventuais processos. Os sujeitos, no caso assujeitados, arcam com o ônus, na declaração trazida do discurso jurídico, a partir da decisão do Supremo Tribunal Federal de que doença contraída no ambiente de trabalho seria indenizável pelo empregador.

O registro do documento a seguir, exarado pelo Governo do Estado do Paraná (Casa Civil, Secretaria de Estado da Educação e do Esporte), é longo. Dele não foi retirado um excerto, de modo a demonstrar todo o conjunto de declarações que envolvem: "afirmo estar ciente" dos protocolos, do agravamento dos riscos, do que deve ser feito nos mais diversos casos. A ser assinado por estudantes e seus responsáveis, o anexo inclui, ainda, uma observação final para os "profissionais da educação". Parece sugerir que ninguém está seguro, mas que todos podem "optar" por correr os riscos. Trata-se do "Termo de Responsabilidade e Consentimento Livre em Situação de Pandemia de Covid-19”.

$\mathrm{Eu}$, portador do CPF número:___ responsável pelo estudante , afirmo estar ciente sobre os protocolos de segurança necessários durante a pandemia de Covid-19, bem como afirmo ciência do estado de transmissão comunitária do novo Coronavírus.

Considerando que se trata de um agente patológico que pode afetar qualquer membro da comunidade escolar e de seu entorno e que, muitas vezes, esse agente pode ser assintomático em algumas pessoas, declaro que estou ciente do agravamento dos riscos que envolvem o retorno às aulas presenciais, não podendo responsabilizar a instituição de ensino, bem como o Governo do Estado do Paraná por eventual contaminação ou desenvolvimento da doença.

Declaro estar ciente de que, caso o estudante seja contaminado com a Covid-19, todos os membros da família deverão ficar em isolamento.

Declaro que o estudante matriculado nesta instituição de ensino não apresentou, nos últimos 14 (quatorze) dias nenhum dos sintomas de contaminação, tais como febre, tosse ou que teve diagnóstico de infecção pelo Covid-19.

Declaro que entrarei em contato com a instituição de ensino caso o estudante presente [sic] quaisquer sintomas causados pela infecção do Covid-19. 
Declaro que o estudante está ciente de que necessita usar constantemente a máscara de tecido assim como realizar a correta higienização das mãos por meio de lavagens com água e sabão e por uso do álcool em gel.

Declaro que o estudante, mesmo retornando ao modelo presencial, necessita continuar a realizar as atividades remotas.

Entendo que este momento é de extrema gravidade e que todos os profissionais de educação, mesmo seguindo todas as orientações de saúde, têm risco de contaminação pessoal (RAMIRES, 2020).

A constituição do sujeito do último parágrafo é digna de nota, na medida em que extrapola o assujeitamento de pais e alunos e se refere a um suposto "entendimento" pelos profissionais de educação. Esses últimos raramente são sujeitos que falam, são entrevistados ou mesmo ouvidos. Deles tem sido subtraído o caráter de autoridade, por mais que sejam especialistas no tema e vivenciem os problemas cotidianamente.

No enredo da pandemia, espera-se que os professores sejam ágeis e criativos, já que cabe a eles tomar todas as iniciativas para chegar aos alunos. No entanto, nos embates, eles têm sido vozes ausentes, como registra a professora Marcia Friggi, da rede estadual de ensino em Santa Catarina:

Fomos pegos de surpresa, como todos. A maioria de nós nunca estudou para dar aulas a distância. Aprendemos na marra, no susto. Nossa casa se transformou em estúdio. Nosso celular em instrumento de trabalho e voz para dez turmas, cerca de quatrocentos alunos e mais seus pais (no meu caso). Em tempos de aulas presenciais, meu celular estava sempre no silencioso para não perturbar, agora também porque muitos alunos e pais não respeitam dia nem horário. Trabalhamos em duas plataformas e quatro frentes: Classroom, WhatsApp, diário on-line e material impresso. [...] Não há como dar conta de aulas presenciais e a distância ao mesmo tempo, se for assim, os que não morrerem de Covid19, vão morrer de exaustão. Ainda tem as lives, quase todo dia, para que os professores escutem, escutem, escutem. [...] Mais que ouvir, necessitamos também falar e, acima de tudo, precisamos ser ouvidos! (FRIGGI, 2020).

No excerto anteriormente citado, o tom é de reivindicação e a modalidade é categórica. Chega a ser peremptório: "os que não morrerem de Covid-19, vão morrer de exaustão." No mesmo texto, a professora menciona programa de TV abordando as escolas na pandemia: "não falou dos professores, nunca, uma única vez." Essa constatação permite verificar que a situação dos professores é mais grave do que no passado recente, quando seu lugar era posto na contradição de obstáculo e protagonista das reformas educacionais (EVANGELISTA; SHIROMA, 2007) e a tendência já era de que não falassem, mas fossem falados.

No Rio de Janeiro, o SEPE (Sindicato dos Profissionais da Educação) foi à Justiça para tentar impedir a volta às aulas. Em assembleia conjunta com o SINPRO (Sindicato dos Professores do Município do Rio de Janeiro e Região), que representa os professores da rede privada, foi aprovada greve para tentar impedir a volta às aulas presenciais, com uma denominação que a distingue das anteriores, comumente expressas pela luta por melhores salários e condições de trabalho: "A GREVE PELA VIDA" (CONTEE, 2020).

Também é importante considerar o discurso do sindicato patronal (Sindicato dos Estabelecimentos de Educação Básica do Rio de Janeiro - Sinepe). Visando afastar os pedidos de abatimento no valor das mensalidades, com liminares favoráveis e contrárias, um vídeo institucional, pondo em xeque a efetividade do distanciamento social, viralizou nas redes sociais. Retirado do ar pelo site que o veiculava, o vídeo, contendo 
imagens de adultos e crianças em salas de aula e ao ar livre, tinha como narração ao fundo um discurso patronal que ia de encontro às recomendações da OMS e a infectologistas do mundo todo (SINDICATO..., 2020).

Na narração citada, que apresentava perspectiva de as escolas estarem preparadas para retomar as atividades presenciais, o discurso se arvora a determinar o que seja ou não ciência:

Vimos que ciência é a vacina. Estudos só confundiram. Trancar todos em casa não é ciência. Confinar é desconhecer, ignorar, subtrair vida, é fragilizar, é debilitar, mexer com o emocional (CÁSSIO; CORTI, 2020).4

Nesse excerto, o sujeito “nós", marcado na desinência verbal, está posicionado como critério absoluto de verdade. Embora remédios e vacina correspondam ao objetivo maior do enfrentamento à pandemia, a desqualificação dos estudos ("só confundiram”) configura a negação da ciência. Após a afirmação peremptória inicial, a incidência de mais um verbo no passado sugere ter havido, de fato, a superação. O isolamento social, retratado a partir da escolha lexical ("trancar todos em casa"), remete a uma violência, não à necessidade de conter a propagação do vírus. As definições de "confinar" completam a desqualificação de tudo o que não for aceito por aquele "nós". Contudo, a repercussão, extremamente negativa, levou ao seu apagamento do vídeo pela página específica.

Os últimos dois excertos evidenciam a importância da análise do aspecto pragmático dos discursos, em dois sentidos: 1) o da explicitação do relacionamento intersubjetivo nas condições da sua produção, permitindo detectar diferentes elementos do contexto de situação; e 2) o da verificação do comprometimento do sujeito com as formulações que faz: objetivas ou subjetivas, mais ou menos categóricas etc. Em outras palavras, o estudo da modalização permite caracterizar a posição do enunciador em relação àquilo que diz.

Finalmente, fosse esta uma análise de conteúdo, seria fácil afirmar que esses dois últimos excertos são diametralmente opostos. Entretanto, sendo uma ACD, que envolve os mecanismos da produção dos sentidos, é possível constatar que a indignação da professora e a postura agressiva do sindicato patronal, mesmo remetendo a sentidos tão diversos, assumem modalização categórica muito próxima.

Logo, para trabalhar as múltiplas determinações dos discursos supracitados, é preciso abordar as condições de possibilidade da sua produção.

\section{Condições de Possibilidade}

Objetivando o discurso na sua relação dialética com a realidade social, esta seção configura uma forma de mapeamento do dizível em tempos de pandemia. Neste movimento, dois pressupostos devem ser retomados: 1) os discursos, como já dito, não são independentes das condições objetivas em que são produzidos; e 2) as questões relativas à escola não têm origem na pandemia, mas são potencializadas por ela.

Objetivamente, tão logo detectada a pandemia, a necessidade de isolamento social determinou o fechamento de espaços caracterizados pela aglomeração ou pela convivência muito próxima. Além do comércio, com fortes repercussões econômicas, foi assim com teatros, cinemas, restaurantes, shows etc. Foi assim também com as escolas. Os espaços culturais permaneceram fechados, aguardando o momento da "flexibilização" das regras. Só meses depois foram buscadas alternativas como lives, apresentações em novas formas de drive-in e até a construção de grandes bolhas para interagir sem contato físico.

Quanto às escolas, houve muita pressão para que fossem rapidamente substituídas pelo ensino remoto emergencial, o que implica duas questões que não podem ser evitadas e assumem sentidos diversos. A primeira remete ao que seria a posição central da escola na sociedade. A segunda aponta para a possibilidade 
de que tal posição seja ocupada por alternativas de fazer chegar conteúdos aos alunos, mantendo-os "ativos", mesmo que dispersos.

Com o Governo Federal se eximindo da esperada liderança, os embates para o enfrentamento da pandemia têm se dado nos níveis estadual e municipal, com muitas discussões acerca das regras a serem seguidas, comumente lexicalizadas como protocolos, expressos por cores e/ou números, tendo como horizonte a sua "flexibilização", ou, em outras palavras, o abandono das restrições devidas à Covid-19, de acordo com os imperativos econômicos.

Havendo demasiados riscos na reabertura das escolas, com vários países revendo sua decisão diante do número significativo de novas infecções, a única alternativa tem sido o chamado "ensino remoto emergencial". De qualquer modo, é importante registrar que essa alternativa configura uma forma de substituição tecnológica da escola, em função de necessidades até então inusitadas. Também merece atenção o fato de que ela implica algum nível de inclusão digital, condição necessária, mas não suficiente, representada por equipamentos de informática e pacotes de dados, o que fortalece a submissão ao "capital educador" (SOUZA; EVANGELISTA, 2020).

A condição de ensino remoto emergencial é a única aplicável à situação. Não é possível falar em ensino a distância, já que esse supõe algum nível de regulação. Também não é possível falar em ensino on-line, dadas as abissais desigualdades entre os alunos. Portanto, a designação escolhida dá conta dos vários aspectos envolvidos, desde a série de estratégias para viabilizar a proposta até os modos de "entrega" dos conteúdos aos alunos, com a vantagem adicional de pontuar o seu caráter emergencial.

Como apontado na seção anterior, a palavra de ordem é "reinvenção". Embora "reinventar-se" retome uma suposta invenção primeira, trata-se apenas de fazer "algo" inusitado nas condições excepcionais, com vistas à sobrevivência. Por outro lado, por coerência com as orientações teórica e metodológica assumidas, é preciso indagar as múltiplas determinações deste "algo". Buscando o seu núcleo sólido, é imperativa a consideração de que o modelo hegemônico de incorporação das TIC à educação tem sido marcado pela ideia de substituição dos diferentes elementos nos mais diversos contextos.

Nos discursos dos organismos multilaterais para os países periféricos, por exemplo, tem havido como que um descolamento de escola e aprendizagem, a partir do foco nessa última. É o que se verifica no plano de ações educacionais para o decênio 2011-2020 (BANCO MUNDIAL, 2011), sob o argumento de que tem havido "aumento da escolaridade, sem aumento da aprendizagem".

Essa relação ganha destaque ainda maior no Relatório sobre o Desenvolvimento Mundial de 2018 (BANCO MUNDIAL, 2018), em que a primeira frase do texto assegura que "escolaridade não é o mesmo que aprendizagem", para, em seguida, desenvolver o argumento de que estar na escola não necessariamente significa ter aprendido algo. O documento assevera que escolaridade sem aprendizagem não é apenas uma oportunidade desperdiçada, mas também uma grande injustiça e que atualmente vivemos uma crise de aprendizagem.

Ainda que não haja consenso quanto à suposição da sinonímia (escolaridade = aprendizagem), do ponto de vista discursivo, é relevante pontuar que não se trata das escolas concretas, mas de um mecanismo de sufixação tradicional que, através de -(i)dade, permite formar substantivo abstrato a partir do adjetivo. Em outras palavras, o Banco opta por trabalhar com uma abstração, não com a realidade concreta. Além disso, o pronome indefinido ("algo" = qualquer coisa) é ressignificado para caber na asserção peremptória que inaugura o texto.

Também é relevante sublinhar que a ressignificação de aprendizagem tem sido uma constante em diferentes formulações do Banco Mundial (BARRETO; LEHER, 2008). Nelas, são promovidas inversões bastante significativas, como: "a aprendizagem precisa se tornar mais flexível e diferenciada para permitir mecanismos de distribuição (delivery) alternativos” (BARRETO; LEHER, 2008, p. 427). As formulações 
chegam a incluir a expressão “acesso à aprendizagem”, como se essa última não apenas devesse ser subordinada aos mecanismos de distribuição, mas tivesse deixado de ser um processo interno.

No caso brasileiro, é importante dimensionar o imaginário que permite deslocamento de um mote conhecido - "de não se aprende somente na escola para não se aprende na escola" (BARRETO et al., 2006, p. 40) -, em que a mudança é materializada como supressão, bem como o movimento analisado por Freitas, tratando dos reformadores empresariais da educação, no movimento "da desmoralização do magistério à destruição do sistema público" (2012, p. 379).

Para encaminhar ambos, uma primeira observação é a de que a frequência da menção a ensino tem sido cada vez menor, assim como cada está vez mais associada a complementos como conteúdos e níveis específicos. Já a aprendizagem tem sido cada vez mais recorrente, configurando inegável desequilíbrio entre os termos do par. É como se essa última prescindisse do ensino.

Além da aprendizagem flagrantemente ressignificada, é oportuno recorrer ao destaque dado por Chauí (1999) às inversões representadas pela substituição da lógica da produção pela da circulação e da lógica do trabalho pela da comunicação. Essa última, por sua vez, na medida do fetiche tecnológico, também aparece invertida no que Zuin (2006) caracterizou como o estabelecimento da supremacia da comunicação secundária sobre a primária.

No desmonte do par, uma relexicalização representa um movimento-síntese: não se fala mais em "materiais de ensino" e sim em "objetos de aprendizagem" (OA), no enredo que Saviani (2007, p. 1253) denominou "pedagogia de resultados", em sua conjugação com o determinismo tecnológico e a racionalidade instrumental. A intensificação do uso das TIC segue o caminho percorrido nas fábricas, pela conversão da subsunção formal em subsunção real do trabalho ao capital. Ainda que as TIC sejam, de fato, o elo entre diretrizes curriculares baseadas em competências e avaliações unificadas centradas nos produtos, o enredo mantém sua mistificação, com o reforço das parcerias público-privadas patrocinando a encenação. Com o conhecimento circulando em software, vídeos ou mesmo materiais impressos, um único docente pode atender a um número muito maior de alunos, permitindo cortar custos, com a vantagem adicional de uma educação mais flexível e condizente com o mundo "globalizado": podendo ser até mesmo a distância e em menor tempo! (BARRETO, 2012).

O que permite a centralidade dos OA é a sua representação como espécie de fórmula independente das condições objetivas nos mais variados contextos. São "aulas" prontas, reutilizáveis, depositadas em "bancos", podendo ser acessadas com base em temática e nível de ensino, no enredo do deslocamento dos sujeitos para os objetos.

Nesse ponto, cabe assinalar que, a despeito da expressão “objetos de aprendizagem” ser a tradução literal de learning objects, na década de 1990, a expressão distance learning foi traduzida como educação ou ensino a distância. Logo, parece razoável supor que tenham mudado significativamente as condições de possibilidade de escolhas lexicais que denotem o esvaziamento do trabalho docente.

Entre as condições citadas, é preciso caracterizar as formas de substituição tecnológica do trabalho docente: 1) a total, representada pelo ensino a distância (BARRETO, 2010); e 2) a parcial, não envolvendo exatamente a retirada do professor da sala de aula, mas diferentes formas de lhe subtrair o protagonismo (BARRETO, 2016). Substituição, no caso, não implica algum tipo de juízo de valor, mas o fato concreto de que as TIC passam a ocupar o lugar dos elementos constitutivos dos processos pedagógicos.

Na promulgação da Lei de Diretrizes e Bases da Educação Nacional (Lei n. 9.394, de 20 de dezembro de 1996), a instituição do EaD merece destaque discursivo pelas condições da sua introdução, feita na seção III, art. 32, $\$ 4^{\circ}$ : “O Ensino Fundamental será presencial, sendo o ensino a distância utilizado como complementação da aprendizagem ou em situações emergenciais." Em outras palavras, o EaD é inscrito a partir do seu contraponto: o ensino que, tal como conhecido e praticado nos mais variados espaços pedagógicos, 
prescinde de adjetivação. Assim, a expressão "ensino presencial" funciona como estratégia discursiva para legitimar o ensino a distância.

Essa qualificação do ensino (presencial) instaura de pronto um lugar da diferença: na medida em que o ensino a distância está sempre associado às "novas linguagens" das "novas tecnologias", o ensino presencial, marcado pelo trabalho docente, pode ser posto como velho e até destituído de valor. Nesses termos, a grande novidade discursiva é a expressão cunhada: a qualificação que desqualifica, desgasta, esvazia. Ademais, não deixa de remeter a um possível apagamento em médio ou longo prazo, em diferentes composições do ambíguo "ensino híbrido".

A aproximação de educação e tecnologias, com o acesso às últimas extrapolando as práticas sociais extraescolares e chegando ao espaço institucionalizado da educação, fica marcada pela interposição da "distância", já configurada na criação de secretaria específica para dar conta da incorporação das TIC. A denominada Secretaria de Educação a Distância traz duas condições importantes para esta análise. A primeira delas está na identificação da meta como movimento de "levar para a escola pública toda a contribuição que os métodos, técnicas e tecnologias de educação a distância podem prestar à construção de um novo paradigma para a educação brasileira”. A suposição de que tais métodos, técnicas etc. estejam consolidados é aprofundada pelo que pode ser encarado como uma espécie de rota de colisão entre os campos em questão, considerando a explicitação do sujeito capaz de realizar a dita mudança paradigmática: "um sistema tecnológico - cada vez mais barato, acessível e de manejo mais simples."

Cabe enfatizar que o $\mathrm{EaD}$ teve como foco quase exclusivo a formação de professores, ainda que a proposta tenha tido a intenção manifesta de expandir o Ensino Superior a baixíssimo custo, próximo de zero. Por outro lado, tratar o $\mathrm{EaD}$ e o ensino presencial como "modalidades" não dá conta das questões que extrapolam o modus operandi. São outras concepções de ensino, de aprendizagem e, em última análise, de "formação" que estão em jogo. Daí a importância da noção de substituição tecnológica, sempre marcando que não se trata de substituir simplesmente o professor, mas todo o processo de trabalho docente.

A segunda configuração, indissociável da proposta de $\mathrm{EaD}$ e mantendo a perspectiva da tecnologia como estratégia de controle, é a substituição tecnológica parcial, em que o professor não é retirado da cena, mas relegado a um papel secundário, tendo suas ações tentativamente reduzidas a aspectos como o controle do tempo necessário à execução de tarefas determinadas e, como suporte, materiais veiculados nas/pelas TIC. Essa última perspectiva, menos visível que a primeira, completa a estratégia de alijar o professor da totalidade do processo de trabalho docente, notadamente no que diz respeito ao planejamento e à avaliação.

Deixa-se de falar em materiais de ensino em nome dos "objetos de aprendizagem", promovendo uma espécie de celebração do esvaziamento do processo de trabalho docente. Nesses objetos, o investimento inicial é compensado pela reutilização quase ilimitada com os mais diversos alunos, em um movimento de padronização que favorece o "gerenciamento" da aprendizagem.

Na produção dos objetos de aprendizagem, algumas secretarias tiveram destacada atuação. Como exemplo, vale citar a Educopédia, plataforma colaborativa produzida em parceria da Secretaria Municipal de Educação do Rio de Janeiro com várias instituições privadas. ${ }^{7}$ Os professores das escolas públicas, por sua vez, enfrentaram entraves como a dificuldade de conexão à Internet por meio de táticas como a gravação prévia das aulas digitais em pen drives.

Mesmo sem entrar no mérito do material veiculado, seu inegável caráter substitutivo é defendido na página http://www.rio.rj.gov.br/web/sme/educopedia como armazenador de todo o conteúdo preconizado pelas orientações curriculares de cada ano e de cada disciplina, divididas em 32 aulas digitais que cobririam todas as semanas do ano letivo, à exceção daquelas destinadas a avaliações e revisões.

Nesse momento, é possível verificar que instituições privadas têm assumido a liderança de iniciativas 
semelhantes, em condições de produção bastante favoráveis. São as chamadas edtechs, forma contraída inscrita como inovação, que sugere uma espécie de fusão de educação e tecnologia. Entretanto, sua origem na língua inglesa não deixa margem a dúvidas: o substantivo é tecnologia, enquanto educação funciona como adjetivo, como o filão mais destacado de uma produção empresarial que, assumindo simplificações como "boas práticas", teria as respostas para os problemas enfrentados. Novidade mesmo é o contexto flexível no qual se pretende operar: não mais as salas de aula nas escolas, mas a educação identificada a "conhecimento aberto", isto é, não protegido por leis de propriedade intelectual.

Em outras palavras, no momento atual, há uma combinação multifacetada das TIC disponíveis para a veiculação de conteúdos determinados por cima e por fora da escola, remetendo a uma hipótese de substituição radical: a que extrapola a sala de aula e atinge a instituição como um todo.

\section{Perspectivas Pós-pandemia}

Para a análise aqui pretendida, alguns elementos e relações são cruciais: 1) os movimentos em torno de vacinar a população; 2) as políticas educacionais, nos seus variados aspectos, sustentando "novos" discursos sobre o ensino (remoto e híbrido); e 3) o uso intensivo, na escola pública, de plataformas de poderosos grupos privados, reunidos no acrônimo GAFAM (Google, Apple, Facebook, Amazon, Microsoft) e na expressão "big five".

Desde a detecção da pandemia, vacina era a palavra-chave para as necessidades e os desejos do conjunto das sociedades, à exceção dos que professavam o discurso negacionista em relação à ciência. Essa, por sua vez, foi capaz de produzir tal vacina em tempo recorde e, cerca de um ano depois, a corrida passou a ser no sentido da imunização coletiva. Na contramão, o governo brasileiro continuou negando a doença e propagando remédios ineficazes, em atuação que foi vista como uma espécie de "necropolítica" (MBEMBE, 2018), atrasando muito a aquisição do imunizante ansiosamente aguardado pelos profissionais tanto da educação como de todas as áreas.

Em outras palavras, aqui não há vacinas para todos; nem mesmo para atender aos grupos definidos como prioritários. Vale acrescentar que a posição dos professores nessa lista não é compatível com a alardeada importância da escola. Ademais, há uma campanha de vacinação interrompida pela falta do produto e até do principal ingrediente para produzi-lo. Ao mesmo tempo, a "campanha", sustentada pelo consórcio de veículos de imprensa, é materializada em uma expressão que merece ser pontuada (“Vacina sim!"), já que se reporta diretamente ao "não" inscrito no negacionismo científico.

No movimento de promover a reabertura das escolas, não é possível ignorar a realidade posta a nu durante a pandemia: as condições nas quais essas instituições têm operado. Sua base física em geral é precária, com espaços muito limitados, ventilação insuficiente e difícil acesso à água. Ao longo de todo o processo, as discussões acerca da escola têm sido pautadas em protocolos sanitários como discursos eminentemente técnico-científicos. Entretanto, os parâmetros de distanciamento nas salas de aula têm sido "relativizados", visto que nem sequer as escolas privadas de elite teriam plenas condições de funcionamento. O que dizer das escolas e universidades públicas, como lócus de formação?

É possível afirmar que o discurso dos protocolos tem produzido mais efeitos práticos do que o pedagógico, que há muito vem contestando o número excessivo de alunos (até 45) nas salas de aula. Entretanto, permanecem os embates acerca do lugar da escola pública nas relações sociais: menos alunos por turma significam a presença de mais professores, em uma perspectiva que aponta para a educação institucionalizada como investimento, não como despesa. 
É forçoso reconhecer que os indicadores do presente não apontam para mudanças significativas nas condições em que essas instituições operam. As perspectivas de financiamento para o futuro próximo não são animadoras. Em 2021, a expectativa é de que o MEC promova significativo corte de verbas de universidades e institutos (AMARAL, 2020). É marcante o deslocamento dos recursos sociais na direção do capital. As universidades, em estrangulamento financeiro agravado pela Emenda Constitucional n. 95, de 15 de dezembro de 2016, também conhecida como "PEC da Morte", passam a ter autorização para que todos os cursos presenciais tenham até $40 \%$ da carga horária a distância. ${ }^{8}$

No que tange à educação básica, a aprovação, pelo Congresso, do novo Fundeb (Fundo de Manutenção e Desenvolvimento da Educação Básica e de Valorização dos Profissionais da Educação - Projeto de Lei n. 4372/20) soa como um alento, por pelo menos duas razões: 1) o fundo passa a ser permanente; e 2) a ampliação do repasse do Governo Federal, dos atuais 10\% para 23\% do total do fundo, de forma escalonada, até 2026. Entretanto, não há como minimizar a aspereza da disputa pelos recursos públicos disponibilizados.

Nos dois cenários, universidades e escolas públicas, ensino remoto (não raro lexicalizado como ensino a distância) e ensino híbrido são as alternativas mais celebradas. Uma abordagem técnica estaria centrada nas suas especificidades. Uma tentativa de aproximação pela via legal destacaria o proibido e o cabível nos diferentes níveis. Aqui, o foco é um elemento comum às duas alternativas: a expropriação do trabalho docente, levada ao limite (e até para além dele) pela entrada das grandes corporações no ensino público.

Retomando a seção anterior quanto às condições da utilização do ensino a distância no Ensino Fundamental, merecem destaque a complementaridade e a emergência. Em meio à pandemia, como negar a emergência? Por outro lado, não podem ser desconsideradas indagações acerca da duração que pode ter uma emergência e da complementaridade como remissão ao chamado "ensino híbrido".

Se há um consenso entre os embates na pandemia, ele diz respeito ao acesso às tecnologias da informação e da comunicação. Afinal, está aí um passo importante para tentar deter os mecanismos de exclusão especialmente dos alunos das escolas públicas (ADRIÃO; DOMICIANO, 2020). Todavia, esse consenso acaba restrito ao plano nocional, considerando as desigualdades de acesso e as diferenças de modos de acesso às tecnologias. Nem mesmo o FUST (Fundo de Universalização dos Serviços das Telecomunicações), compromisso assumido quando da sua privatização nos anos 1990, tem sido aplicado de modo a viabilizar a construção de uma necessária rede. ${ }^{9}$

A defesa da realização de aulas on-line tende a desconsiderar a inexistência de uma Internet banda larga de qualidade, acessível a todos e em toda parte. Também nas universidades, a presença de alunos em situação de vulnerabilidade socioeconômica, sem as condições necessárias ao acesso à Internet, tem feito com que seja oferecido o "auxílio inclusão digital", por meio do fornecimento de sim card com franquia de serviço de dados móveis. Nos diagnósticos apresentados, não são consideradas as condições de vida dos alunos tampouco apontadas quaisquer estratégias de inclusão social, como renda básica.

Em relação aos professores, um discurso tende a celebrar uma espécie de ensino remoto romantizado, em que não são poupados esforços para entregar materiais aos alunos residentes em locais de difícil acesso. ${ }^{10}$ Outro discurso exorta os professores a alguma forma de capacitação para o uso de grandes plataformas, a fim de "levar aos alunos" os conteúdos e as atividades requeridos.

Dimensionando esse embate discursivo, lives importantes têm tratado da necessária agenda póspandemia. Entre elas, este artigo traz inscrito um diálogo com as formulações de Nelson Pretto ${ }^{11}$ e Roberto Leher, ${ }^{12}$ em lives realizadas no ano de 2020.

O primeiro autor, centrado na universidade pública, aborda o desafio da construção de uma "rede federada", com soluções colaborativas, visando fortalecer a Rede Nacional de Ensino e Pesquisa (RNP) e superar a atual submissão aos termos de acesso e consentimento em que são baseadas as licenças de uso, conformando 
a adesão acrítica. O segundo, pensando escola e universidade, também defende o desenvolvimento de plataformas que rompam com a lógica empresarial na determinação do que é dado a pensar nas instituições de ensino. Chamando a atenção para o fato de que os protocolos sanitários estão em "completo desacordo com as condições objetivas das escolas", Leher aborda as muitas mudanças estruturais requeridas.

Os autores dimensionam a "batalha" (consultar a nota 11 sobre a live de Pretto do ano de 2020) a ser travada e a perspectiva de "renuclear os alunos" (consultar a nota 12 sobre a live de Leher do ano de 2020), de modo a impedir que a escola seja reduzida a um espaço físico a que os alunos podem recorrer para ter acesso a tecnologias e a algumas possibilidades de tutoria, como na implantação dos polos de ensino a distância, nos anos 1990. Em outras palavras, as formulações desafiam o atual desenho do movimento que vai do ensino remoto emergencial e flexível, no qual "tudo" é cabível, para o ensino híbrido (blended), concebido como uma mistura do ensino presencial com o ensino on-line e celebrado como inovação educacional. Fica a indagação: o que cabe nele? Também fica caracterizada a apologia da inovação em si, com o trabalho pedagógico entregue aos interesses empresariais. Os professores ficam capturados entre plataformas e aplicativos que, em última análise, sugerem que sua formação não serve à "nova realidade educacional".

Do ponto de vista discursivo, o adjetivo (novo), já bastante frequente na expressão "novo normal", serve à naturalização do que quer que seja apresentado como "real”. Daí a necessidade de começar pelo enfrentamento das ditas novidades, em várias frentes. Trazendo uma máxima brechtiana, Benjamin pode ser uma inspiração: "não partir do antigo bom, mas do novo ruim" (2017, p. 64).

\section{Notas}

1. Disponível em: https://www.facebook.com/messenger_media/?thread_id=100001649399198\&attachment_ id=3259062310824868\&message_id=mid.\%24cAAAAAPPeJE95shYX1lzgNDPr0IIc. Acesso em: 12 set. 2020.

2. Imagem sintética da desigualdade das condições de vida dos estudantes. Disponível em: https://www.facebook. com/messenger_media/?thread_id=100037358802089\&attachment_id=1378716542313071\&message_id=mid.\% 24cAAAACEIoZXh32lPPJ1xqQ6AvIkVD. Acesso em: 27 jul. 2020.

3. O site em questão envolve um coletivo de jornalistas com o ideal de produzir conteúdos de forma alternativa e independente.

4. A transcrição completa do vídeo é feita no artigo intitulado "A roleta-russa da abertura das escolas", já referido.

5. No original: "more schooling, little learning."

6. Conforme a página oficial no portal do MEC, até a sua desativação, em 2011.

7. Disponível em: http://www.rio.rj.gov.br/web/sme/educopedia. Acesso em: 2 ago. 2020.

8. Trata-se da Portaria n. 2.117, de 6 de dezembro de 2019, que dobra o limite de $20 \%$ anterior, o que significa quase a metade dos cursos presenciais desenvolvida a distância.

9. De acordo com a Lei n. 9.998, de 17 de agosto de 2000, destina a contribuição de $1 \%$ sobre a receita operacional bruta, decorrente de prestação de serviços de telecomunicações nos regimes público e privado. Disponível em: https://www.anatel.gov.br/setorregulado/arrecadacao-fust. Acesso em: 28 ago.2020.

10. Disponível em: https://g1.globo.com/pe/pernambuco/noticia/2020/07/24/professor-pedala-mais-de-setequilometros-para-ajudar-alunos-que-nao-tem-acesso-a-aulas-online.ghtml. Acesso em: 25 jul. 2020. 
11. Live “Plataformas Privadas Na Educação Pública - Quem ganha com isso?” Disponível em: https://www.youtube. com/watch?v=1AHAC-PZPIo. Acesso em: 21 ago. 2020.

12. Live "EXEPEPe - Executiva Paraense dxs estudantes de Pedagogia: A crise da Covid-19 e suas implicações para a educação e a pedagogia”. Disponível em: https://www.facebook.com/exepepe.mepe/videos/2415228842104865. Acesso em: 10 ago. 2020.

\section{Referências}

ADRIÃO, T.; DOMICIANO, C. A. Novas formas de privatização da gestão educacional no Brasil: as corporações e o uso das plataformas digitais. Retratos da Escola, Belo Horizonte, v. 14, n. 30, p. 668-684, set./dez. 2020. https://doi.org/10.22420/rde.v14i30.1223

AMARAL, L. MEC deve cortar R \$ 1,4 bi de verba de universidades e institutos em 2021. Uol, Educação, Brasília, DF, 7 ago. 2020. Disponível em: https://educacao.uol.com.br/noticias/2020/08/07/mec-deve-cortar18-do-orcamento-de-universidades-e-institutos-em-2021.htm. Acesso em: 10 ago. 2020.

BANCO MUNDIAL. Learning for all: investing in people's knowledge and skills to promote development. World Bank Education Strategy 2020. Washington: The International Bank for Reconstruction and Development, 2011. Disponível em: http://documents1.worldbank.org/curated/en/685531468337836407/ pdf/644870WP0Learn00Box0361538B0PUBLIC0.pdf. Acesso em: 15 jul. 2020.

BANCO MUNDIAL. Relatório sobre o desenvolvimento mundial de 2018: aprendizagem para realizar a promessa da educação. [S. 1.]: Banco Mundial, 2018. Disponível em: https://openknowledge.worldbank. org/bitstream/handle/10986/28340/211096mmPT.pdf?sequence=28\&isAllowed=y. Acesso em: 22 jul. 2020.

BARRETO, R. G. A formação de professores a distância como estratégia de expansão do ensino superior. Educação \& Sociedade, Campinas, v. 31, n. 113, p. 1299-1318, 2010. https://doi.org/10.1590/ S0101-73302010000400013

BARRETO, R. G. A recontextualização das tecnologias da informação e da comunicação na formação e no trabalho docente. Educação \& Sociedade, Campinas, v. 33, n. 121, p. 985-1002, 2012. https://doi.org/10.1590/ S0101-73302012000400004

BARRETO, R. G. Entre a Base Nacional Comum Curricular e a avaliação: a substituição tecnológica no Ensino Fundamental. Educação \& Sociedade, Campinas, v. 37, n. 36, p. 775-791, 2016. https://doi.org/10.1590/ es0101-73302016159933

BARRETO, R. G. Objetos como sujeitos: o deslocamento radical. In: FERREIRA, G. M. S.; ROSADO, L. A. S.; CARVALHO, J. S. (orgs.). Educação e tecnologia: abordagens críticas. 1. ed. Rio de Janeiro: SESES, 2017. v. 1, p. 124-159. Disponível em: https://ticpe.files.wordpress.com/2017/04/ebook-ticpe-2017.pdf. Acesso em: 25 jul. 2020.

BARRETO, R. G. et al. As tecnologias da informação e da comunicação na formação de professores. Revista Brasileira deEducação, Rio de Janeiro, v.31,p.31-42,2006. https://doi.org/10.1590/S1413-24782006000100004

BARRETO, R. G.; LEHER, R. Do discurso e das condicionalidades do Banco Mundial, a educação superior “emerge" terciária. Revista Brasileira de Educação, Rio de Janeiro, v. 39, 423-436, 2008. https://doi. 
org/10.1590/S1413-24782008000300002

BENJAMIN, W. Ensaios sobre Brecht. São Paulo: Boitempo, 2017.

CÁSSIO, F.; CORTI, A. P. A roleta-russa da abertura das escolas. Le Monde Diplomatique, 31 jul. 2020. Disponível em: https://diplomatique.org.br/a-roleta-russa-da-abertura-das-escolas/. Acesso em: 31 jul. 2020.

CHAUÍ, M. Ideologia neoliberal e universidade. In: OLIVEIRA, F.; PAOLI, M. C. (orgs.). Os sentidos da democracia: políticas do dissenso e hegemonia global. Petrópolis: Vozes/Brasília: Nedic, 1999. p. 27-51.

CONTEE [CONFEDERAÇÃO NACIONAL DOS TRABALHADORES EM ESTABELECIMENTOS DE ENSINO]. Assembleia histórica aprova, por ampla maioria, greve pela vida! CONTEE. Notas Públicas, 6 jul. 2020. Disponível em: https://contee.org.br/assembleia-historica-aprova-por-ampla-maioria-greve-pelavida. Acesso em: 12 ago. 2020.

CRIVELLA diz não ver obstáculos à reabertura de escolas porque "crianças são imunes". Jornal Extra, Notícias, Rio, 2 jul. 2020. Disponível em: https://extra.globo.com/noticias/rio/crivella-diz-nao-ver-obstaculosreabertura-de-escolas-porque-criancas-sao-imunes-24512651.html. Acesso em: 2 jul. 2020.

EVANGELISTA, O; SHIROMA, E. O. Professor: protagonista e obstáculo da reforma. Educação \& Pesquisa, São Paulo, v. 33, n. 3, p. 531-541, set./dez. 2007. https://doi.org/10.1590/S1517-97022007000300010

FAIRCLOUGH, N. Discurso e mudança social. Brasília: Editora da UnB, 2001.

FAIRCLOUGH, N. Language and globalization. London: Routledge, 2006.

FREITAS, L. C. Os reformadores empresariais da educação: da desmoralização do magistério à destruição do sistema público de educação. Educação \& Sociedade, Campinas, v. 33, n. 119, p. 379-404, 2012. https:// doi.org/10.1590/S0101-73302012000200004

FREITAS, L. C. Os reformadores empresariais da educação e a disputa pelo controle do processo pedagógico na escola. Educação \& Sociedade, Campinas, v. 35, n. 129, p. 1085-1114, out./dez., 2014. https://doi.org/10.1590/ ES0101-73302014143817

FRIGGI, M. A invisibilidade do magistério brasileiro no delicado processo de retorno às aulas presenciais durante a pandemia. Revistapontocom, 29 jul. 2020. Disponível em: http://revistapontocom.org.br/artigos/ a-invisibilidade-do-magisterio-brasileiro-no-delicado-processo-de-retorno-as-aulas-presenciais-durante-apandemia. Acesso em: 28 jul. 2020.

GUSSO, H. L. et al. Ensino Superior em tempos de pandemia: diretrizes à gestão universitária. Educação \& Sociedade, Campinas, v. 41, 25 set. 2020. https://doi.org/10.1590/es.238957

HODGES, C. et al. The difference between emergency remote teaching and online learning. Educause Review, 27 mar. 2020. Disponível em: https://er.educause.edu/articles/2020/3/the-difference-betweenemergency-remote-teaching-and-online-learning. Acesso em: 28 jun. 2020.

LUCHESE, B. Prefeitura não recarrega cartão de auxílio-merenda e mães de alunos do ensino público do Rio fazem apelo. Portal G1, 2 jul. 2020. Disponível em: https://g1.globo.com/rj/rio-de-janeiro/noticia/2020/07/02/ prefeitura-nao-recarrega-cartao-de-auxilio-merenda-e-maes-de-alunos-do-ensino-publico-do-rio-fazemapelo.ghtml. Acesso em: 3 jul. 2020. 
MBEMBE, A. Necropolítica. São Paulo: N-1 Edições, 2018.

OLIVEIRA, D. A.; PEREIRA JUNIOR, E. A. Trabalho docente em tempos de pandemia: mais um retrato da desigualdade educacional brasileira. Retratos da Escola, Belo Horizonte, v. 14, n. 30, p. 668-684, set./dez. 2020. https://doi.org/10.22420/rde.v14i30.1212

RAMIRES, M. Secretaria de educação do Paraná transfere para os pais a responsabilidade por contaminações no ambiente escolar. Porém.net, 1 ago, 2020. Disponível em: https://porem.net/2020/08/01/secretaria-deeducacao-do-parana-transfere-para-os-pais-a-responsabilidade-por-contaminacoes-no-ambiente-escolar. Acesso em: 2 ago. 2020.

RIBEIRO, E. “A pandemia não é a mesma para todos”, diz a presidente da Fiocruz. DSS Brasil, 10 jul. 2020. Disponível em: http://dssbr.org/site/2020/07/a-pandemia-nao-e-a-mesma-para-todos-diz-a-presidente-dafiocruz/, Acesso em: 08 jul. 2020.

SAVIANI, D. O Plano de Desenvolvimento da Educação: análise do projeto do MEC. Educação \& Sociedade, Campinas, v. 28, n. 100, p. 1231-1255, out. 2007. https://doi.org/10.1590/S0101-73302007000300027

SINDICATO de escolas do Rio critica isolamento social: "Não é ciência”. Uol, Educação, 28 jul. 2020. Disponível em: https://educacao.uol.com.br/noticias/2020/07/28/sindicato-de-escolas-particulares-do-riocritica-isolamento-social.htm. Acesso em: 28 jun. 2020.

SOUZA, A. G.; EVANGELISTA, O. Pandemia! Janela de oportunidade para o capital educador. Contrapoder, 15 abr. 2020. Disponível em: https://contrapoder.net/colunas/pandemia-janela-de-oportunidade-para-ocapital-educador/. Acesso em: 1 jul. 2020.

ZUIN, A. A. S. Educação a distância ou educação distante? O Programa Universidade Aberta do Brasil, o tutor e o professor virtual. Educação \& Sociedade, Campinas, v. 27, n. 96, p. 935-954, out. 2006. https://doi. org/10.1590/S0101-73302006000300014

\section{Sobre a Autora}

RAQUel Goulart BARRETo é graduada em Letras e tem mestrado e doutorado em Educação pela Universidade Federal do Rio de Janeiro (UFRJ). É professora aposentada da Universidade Federal do Rio de Janeiro (UFRJ), concursada na Universidade do Estado do Rio de Janeiro (UERJ), em sua Faculdade de Educação (ProPEd), desde 2003. Teve bolsas de Produtividade em Pesquisa (CNPq) a partir de 2001.

Recebido: 2 set. 2020

Aceito: 11 mar. 2021 